Cristovam Buarque, engenheiro mecânico, doutor em economia pela Sorbonne. Professor do Departamento de Economia da UnB e consultor das Nações Unidas em diversos países da América Latina, na Europa e na África.

\title{
Teoria econômica e meio ambiente
}

Para os demais animais, a sobrevivência de cada indivíduo e cada espécie se dá através de uma mutação direta da natureza, através diretamente do processo de alimentação. Um peixe come diretamente as algas do rio, e é comido por um peixe maior que, por sua vez, é comido por um jacaré, em uma seqüência natural de inter-relações ecológicas.

Para estes animais, o processo de viver e de sobreviver consiste na mesma atividade: eles vivem para comer e comem para viver; como indivíduo e reproduzir-se como espécie; o resto é apenas repouso.

No caso das sociedades humanas, desde os sistemas primitivos, ocorrem duas diferenças em relação aos sistemas de sobrevivência dos demais animais. A primeira grande diferença é que os homens passam a usar instrumentos de produção. Em vez de apropriar-se diretamente da natureza, como fazem os outros animais, com as próprias mãos e bocas, que Georgescu-Roegen chama de instrumentos endossomáticos, o homem usa elementos intermediários: armas e ferramentas, os instrumentos exossomáticos ${ }^{1}$. A segunda diferença é que o homem passou a desenvolver outras atividades (como as culturais), diferenciadas daquelas puramente ligadas à sobrevivência, as quais passam a ser chamadas de trabalho. Como conseqüência aparecem, entre os homens e a natureza, elementos especiais chamados bens econômicos².

Na medida em que os próprios sistemas econômicos se modificam, ao longo da história social (diferentemente da natural dos demais animais), o processo de produção e de distribuição do produto (de bens) se dá conforme leis específicas manten- do apenas a generalidade que se representa na figura a seguir.

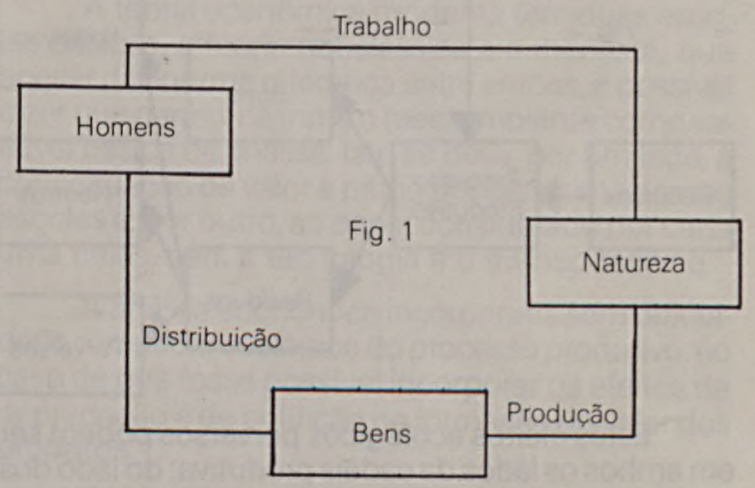

A atividade econômica é, portanto, uma das formas de transformação permanente que envolve a natureza. Mas, é uma forma muito especial, porque ao contrário das demais, ela não serve para criar diretamente novas formas de vida. A atividade econômica, transfórmando a natureza, processa a fabricação de um tipo específico de novos membros da natureza, "artificialmente" obtidos, chamados de bens econômicos. Através do uso destes bens é que o homem consegue sobreviver, reproduzir-se e viver.

Esta característica do processo humano de produção gera, necessariamente, especificidades quanto ao problema ecológico.

$\mathrm{O}$ equilíbrio ecológico tem que ser visto, obviamente, do ponto de vista de "quem" o estuda. Para um jacaré do pantanal pouco importa a poluição das cidades, mas preocupa-o a depredação da vida 
animal no seu ambiente. A perversidade ou bondade ecológica de uma atividade deve, portanto, ser considerada em função do grau de custo ou benefício que a atividade em análise provoca sobre o meio ambiente que serve de suporte à "vida". Naturalmente os animais mantêm um equilíbrio ecológico, uma vez que suas "atividades econômicas" são naturais e dispõem, portanto, de mecanismos realimentadores que controlam a vida e a reprodução do animal, em função de sua ação sobre o meio ambiente. Assim, se uma espécie começa a procriar desmesuradamente, a alimentação começará a escassear e o crescimento demográfico se reduzirá, voltando o sistema ao seu equilíbrio.

O homem conseguiu quebrar esta cadeia de equilíbrio uma vez que seu sistema gera efeitos acelerados, e uma vez que as suas cadeias de produção deixam seqüências abertas. O resultado pode ser que a perversidade ecológica não gere seus próprios mecanismos corretores, sem um custo demasiado elevado, ameaçando, inclusive, segundo alguns, a própria sobrevivência da espécie.

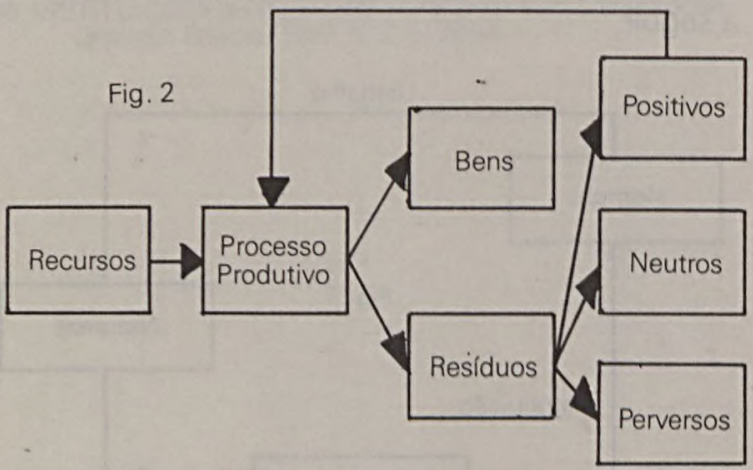

Estes efeitos ecológicos perversos podem s̀er em ambos os lados da cadeia produtiva: do lado dos recursos, esgotando fontes necessárias à vida, ou do lado dos resíduos, gerando poluentes ambientais prejudiciais à vida.

\section{O lado da depredação dos recursos}

O conceito de recursos naturais tem que ser visto historicamente, de conformidade com o nível tecnológico. De acordo com a tecnologia disponível, em cada instante, parte da natureza é considerada recurso. Estes recursos mudam com o tempo, tanto através da incorporação de novos como na aposentadoria de antigos. Assim, por exemplo, até cem anos atrás o petróleo não era um recurso, como da mesma forma, até poucas décadas, o urânio tampouco era um recurso natural (econômico).

Da mesma forma que o avanço técnico vai incorporando novos recursos, ele também vai aposen- tando os antigos, que tornam-se obsoletos. Em um antigo momento na pré-história, a pedra era o único recurso econômico. O gás substituiu nos centros modernos, o uso da lenha como combustível, o plástico substituiu minerais e madeira em grande parte dos setores produtivos de bens de consumo.

Considerando isto, torna-se difícil definir claramente o impacto ecológico da atividade econômica sobre a disponibilidade de recursos. Observa-se, pela figura a seguir, o que ocorre quando uma determinada atividade "consome" uma certa quantidade de recursos. Da soma total que a natureza apresenta, a economia consome, em cada ano, parte da disponibilidade do recurso, com o objetivo de produzir bens.

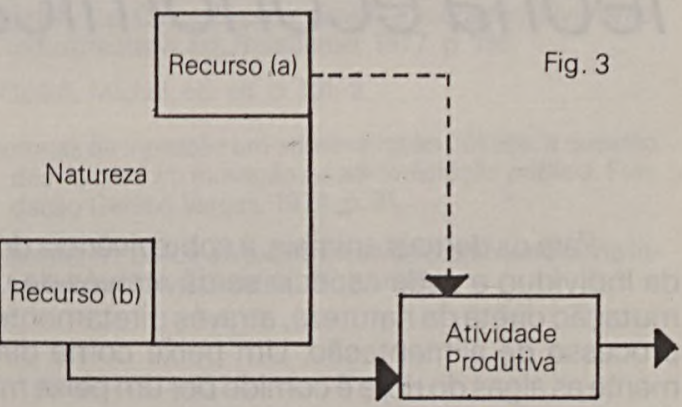

O impacto ecológico que interessa, na análise econômica, seria aquele que, ao esgotar o recurso, gerasse um efeito perverso, sob a forma de: impossibilidade de continuar a atividade econômica; elevação dos custos de produção, provocando redução no consumo. O caso do petróleo indica bem a situação: ao queimar cada barril de petróleo a atividade econômica destrói "definıtivamente" ${ }^{\prime 3}$ este recurso.

A análise, porém, não pode ser feita apenas a partir deste impacto direto, uma vez que o sistema, tomado em sua globalidade, pode corrigir a depredação de recursos sob duas formas: pelo reaproveitamento do próprio recurso (reciclagem), ou pela substituição deste recurso por outro.

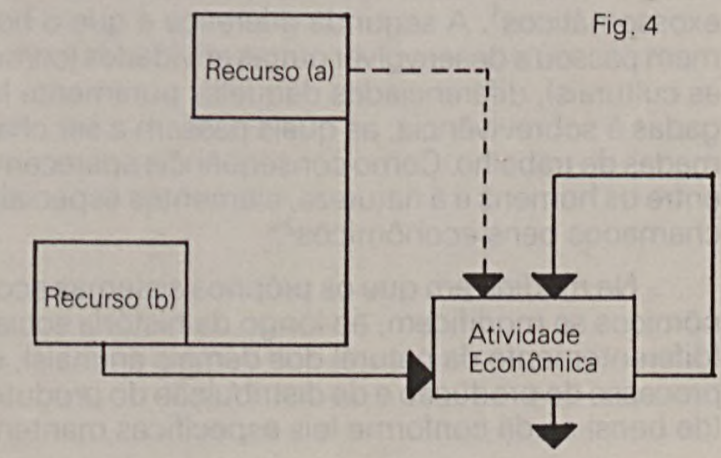


O caso do petróleo serve mais uma vez para indicar esta correção. Através de, por exemplo, um possível reaproveitamento do resíduo de carbono como combustível, ou o desenvolvimento de outras fontes energéticas para substituição do petróleo, sem que a atividade econômica seja sacrificada, nem estancada, nem reduzida, nem tenha seus custos elevados.

Há ainda possibilidade de reduzir o impacto ecológico pelo lado do ajustamento da demanda, reduzindo os requerimentos dos recursos, sem substituí-lo.

O problema da medição do impacto ecológico pelo lado dos recursos deve, portanto, ser o resultado da consideração de:

- tipo natural

- dimensão das reservas: quanto maior, menor o impacto econômico de destruição de uma parte do recurso;

- renovabilidade: possibilidade de renovação natural - o oxigênio através da fotossíntese - faz com que a esgotabilidade seja adiada, às vezes, "ilimitadamente";

- tipo tecnológico

- reciclagem: reaproveitamento dos resíduos, através da reciclagem;

- substitubilidade: substituição do recurso por outro disponível;

- tipo social: "possibilidade de reduzir o consumo sem substituição"4.

\section{O lado da poluição do meio ambiente.}

Da mesma forma que gera destruição no lado dos recursos, a atividade econômica gera efeitos colaterais posteriores à produção. Entre estes efeitos estão, por exemplo, o malcheiro de uma destilaria de álcool; o ruído nas áreas vizinhas às cabeceiras das pistas dos aeroportos; a contaminação dos rios próximos às fábricas de papel; a contaminação do ar próximo às indústrias petroquímicas; etc.

As conseqüências disto podem ser classificadas em dois tipos: efeitos basicamente econômico: como a redução na produção pesqueira devido a resíduos gerados; efeito basicamente social: como as doenças provocadas por resíduos ou pela contaminação do $a r^{5}$.

No que se refere aos efeitos basicamente econômicos localizados em ambientes "fechados", a contabilização dos custos pode ser feita de uma maneira simplificada e representada pela medição das perdas econômicas para a população. É o caso, por exemplo, da contaminação dos rios com a destrui- ção do manancial pesqueiro. Esta medição recai nos mesmos princípios vistos do esgotamento de recursos, o efeito do lado poluente consistindo na destruição de recursos. O efeito passa a ser função - como já visto - da possibilidade de reciclagem dos resíduos, purificando-se o que foi contaminado ou evitando-se a contaminação ${ }^{6}$; recaindo-se mais uma vez nos aspectos tecnológicos da possibilidade de reciclagem.

\section{Os economistas e o meio ambiente}

\section{A visão otimista prevalecente}

Para que a análise econômica tome em conta os impactos ecológicos do processo produtivo, é necessário que a teoria defina métodos de medir estes impactos, tanto do lado da depredação dos recursos, como do lado da poluição ambiental.

Lamentavelmente, porém, as grandes teorias econômicas existentes não têm sido capazes de incorporar o problema do impacto ambiental em suas análises globais.

A teoria econômica moderna tem duas escolas básicas, a teoria neoclássica e a marxista, que apesar da enorme diferença entre ambas, é possível dizer que nenhuma toma o meio ambiente como variável básica de análise. Isto se deve, por um lado, à conceituação de valor e preço por cada uma dessas escolas e, por outro, ao papel considerado por cada uma delas, para a tecnologia e o avanço técnico.

A análise econômica incorporaria sem dificuldade o impacto ecológico do processo produtivo, no caso de que fosse possível incorporar os efeitos de depredação e de poluição na formação do valor dos produtos.

Conforme a teoria neoclássica, o preço dos bens e insumos decorrem apenas do equilíbrio entre a oferta e a demanda pelo respectivo insumo, no curtíssimo prazo.

Para a teoria neoclássica, a escassez é conjuntural e os preços retomam sempre o nível compatível, na medida em que, ao elevar-se, os preços geram um incentivo ao aumento de produção, retomando-se o equilíbrio ${ }^{7}$. Desta forma, a teoria de formação de preços torna-se incapaz de tomar em conta as tendências de longo prazo, decorrentes da provável escassez.

Para o caso da escassez real, devido a alguma forma de esgotamento, a teoria neoclássica prevê a substitubilidade imediata de um recurso por outro, graças ao crescimento no preço do recurso que tende a esgotar-se e, conseqüentemente, a viabilização técnica e o barateamento de novos recursos. 
Neste sentido, dois pressupostos são implicitamente assumidos: primeiro que a tecnologia sempre será capaz de responder criando novos recursos; segundo que isto se dará em um tempo hábil suficiente para evitar riscos de custos econômicos no aparelho produtivo ${ }^{8}$.

Além disso, a teoria neoclássica tem um pressuposto básico que impede, filosoficamente, que a concepção de esgotabilidade possa vir a ser tomada em conta. Isto decorre da visão de que o utilitarismo egoísta é a base da racionalidade econômica. Assumindo esta racionalidade, que implica na maximização do bem-estar social através do interesse dos indivíduos, torna-se impossível considerar a esgotabilidade no longo e médio prazo, uma vez que a preferência temporal do indivíduo toma em conta apenas o curto prazo e o imediatamente em torno à sua pessoa e empresa.

Isto fica claro quando se observa o problema da poluição do ponto de vista da empresa geradora, ou do usuário de um agente poluente. 0 empresário ou o usuário não têm porque considerar espontaneamente o "custo" que provocam, uma vez que estes custos são externos aos seus próprios fluxos de fundos. O desastre que produż o despejo de poluentes em um rio não traz qualquer prejuizo para a fábrica que os produz. Desta forma, seria um "erro" o empresário considerar estes efeitos na análise da performance de sua empresa. O mesmo pode-se afirmar de um motorista que dirige um automóvel nas ruas da cidade.

O custo da poluição é social, logo não é incorporado nas análises individuais de cada agente econômico, não podendo, portanto, ser tomado em conta nas análises econômicas neoclássicas.

A visão marxista do valor tampouco toma em conta a esgotabilidade dos recursos. Isto se deve a dois aspectos: primeiro, para Marx como para os clássicos que o precederam, o valor das coisas é dado pela quantidade de trabalho nelas contido, segundo, a visão marxista da história é necessariamente otimista, vendo o progresso técnico não apenas como ilimitado (desde que superados os entraves das estruturas sociais), mas também como determinante do próprio progresso social.

Esta visão otimista (em relação a Malthus e a Ricardo) torna toda esgotabilidade impossível, uma vez que, segundo ela, desde que superados freios sociais, a tecnologia tende a rapidamente substituir e aposentar os recursos que porventura viessem a ficar escassos. Assim, ao longo do tempo, o valor das coisas não mudam, desde que não mude a quantidade de valor nelas implícitas. Da mesma forma que o sitema neoclássico prevê com os preços, na conceituação marxista a esgotabilidade temporária se traduz no aumento da quantidade de trabalho necessário para obter o recurso e, portanto, o produto 9 . Mas, imediatamente, novas tecnologias produziriam substitutos mais baratos liberando mão-de-obra, desaparecendo a esgotabilidade.

Unindo os neoclássicos e os marxistas, a realidade dos últimos 150 anos demonstrou que a idéia de esgotamento era um conceito absurdamente pessimista desenvolvido por Malthus. De fato, o avanço técnico fez acreditar na ilimitabilidade de potencial humano de inovar tecnicamente, elevando-se constante e enormemente a produtividade humana, ao mesmo tempo que se "criavam" novos recursos e se descobriam formas de renovar e explorar os antigos recursos, mesmo aqueles não-renováveis e com um curto período de esgotamento relativo.

A agricultura é um exemplo desta capacidade. As previsões de Malthus indicavam um rápido esgotamento relativo, no sentido de que não seria capaz de fornecer os alimentos necessários para satisfazer as necessidades crescentes da população. Ricardo colocou o problema em forma mais refinada, mostrando que o crescimento das necessidades levaria a economia a ocupar terras cada vez menos férteis, até o momento em que seriam ocupadas as terras onde todo o trabalho só seria suficiente para repor a vida dos camponeses, não sendo possível a produção de excedente, o que forçaria um estado estacionário para a economia e a demografia.

Estes dois economistas foram desmentidos pela realidade, graças ao fator tecnológico, não reconhecido em toda sua potencialidade, por qualquer dos dois.

A realidade é o que o homem foi capaz de inventar formas produtivas mais eficientes, elevando a produtividade nas terras conhecidas, ao mesmo tempo em que descobria novos recursos no que antes era relegado ${ }^{10}$.

Marx, por sua vez, também previu a tendência ao capitalismo estacionário na medida em que mostrou que a composição orgânica do capital sendo crescente a taxa de lucros cairia até zero. Mas, foi mais otimista que os seus antecessores ao prever que esta taxa de lucros decrescentes, em vez de levar a uma economia estacionária, levaria ao fim do capitalismo, e as modificações estruturais da sociedade fariam com que o socialismo, e depois o comunismo, levassem o homem ao nível ilimitado de abundância e tempo livre.

A rejeição das previsões de Ricardo e especialmente as de Malthus, levaram à rejeição da visão pessimista das limitações dos recursos. Os economistas têm sido, todos, otimistas, dividindo-se apenas entre os neoclássicos, que consideravam a potencialidade ilimitada do capitalismo, e os socialis- 
tas, que entendiam a necessidade de mudanças sociais dando base à abundância econômica.

Não havia, em qualquer das escolas, necessidade de incluir o problema do meio ambiente nas análises. O mercado, para os neoclássicos e as revoluções sociais, para os marxistas, liberariam, automaticamente, as forças tecnológicas capazes de impedir sempre o esgotamento e a poluição.

\section{A redescoberta do meio ambiente}

O que caracteriza os neomalthusianos é a consciência dos "limites do crescimento" econômico, conforme o próprio título do Relatório do Clube de Roma que, em 1970, foi o marco inicial da extensa literatura que assume uma posição parecida quanto aos sintomas do limite, embora discordem quanto ao diagnóstico e quanto às propostas ${ }^{11}$.

O que fez possível o aparecimento do neomalthusianismo e a sua "aceitação", foi o aparecimento de bases técnicas e políticas que se associaram em um certo momento, de forma a permitir a consciência de que, no ritmo atual de consumo e de inovação técnica, é possível prever graves riscos de que os recursos disponíveis não sejam capazes de suportar os requerimentos da economia.

A base técnica pode ser encontrada no desenvolvimento de três instrumentais de análise: as teorias de análise de sistema, que permitiram a formulação de modelos globais, à escala mundial, interrelacionando, qualitativamente, as diferentes variáveis econômicas, tanto no lado do produto como no lado dos insumos; a disponibilidade de dados estatísticos que permitiram quantificar as relações, definindo os coeficientes técnicos específicos para cada insumo, e definindo as tendências do consumo e das produções e, portanto, dos requerimentos em recursos, a nível mundial; as técnicas e os equipamentos de processamento de dados, sem os quais seria impossível manipular as informações contidas nos modelos.

A base política, em parte, graças, certamente, ao próprio Relatório do Clube de Roma e ao pretexto da Guerra do Oriente Médio, deu-se com a tomada de consciência, por parte dos países da Organização dos Países Exportadores de Petróleo-OPEP, de que seu patrimônio era esgotável em prazo relativamente curto, e que a solução era elevar os preços como forma de conservá-lo por mais longo tempo, ou obter, no imediato, o máximo em troca.

Ao lado disto, como a base material das formulações do neomalthusianismo, estava a consciência, a partir dos anos 60, de que o elevado nível de produção e desperdício da sociedade de consumo moderna estavam levando, de um lado, à depredação de recursos e, do outro, a um nível insuportável de poluição ambiental.

O Clube de Roma demonstrou, com projeções estatísticas, a probabilidade de que estes fenômenos tornar-se-iam sumamente graves em um curto prazo de tempo.

Embora os estudos dos neomalthusianos demonstram a redescoberta pelos economistas dos problemas implícitos no impacto do processo produtivo sobre o meio ambiente, na realidade estes estudos não correspondem a análises econômicas. Com raras exceções, estes estudos consistem, exclusivamente, em trabalhos estatísticos de projeções de tendência. As análises se limitam quase sempre à determinação de coeficientes e em projeções, assumindo (ceteris paribus) que as exigências de consumo e os coeficientes técnicos comportem-se, no futuro, da mesma forma que no passado. No máximo, as projeções realizam análises de sensibilidade de forma a definir diferentes cenários possíveis.

Esta posição dos economistas preocupados com o futuro, de comportarem-se basicamente como modelistas e projetistas, decorre naturalmente das limitações da ciência econômica, que não dispõe de instrumentos analíticos que permitam definir a tendência real, uma vez que: o crescimento demográfico tem sido uma variável externa aos modelos econômicos; não pode intervir, como ciência, na definição das modificações sócio-econômicas decorrentes da escassez; não pode prever as evolucões tecnológicas e seus impactos sobre a substitubilidade entre recursos; não é possível conhecer a variação de "preços" para os recursos próximos da escassez real.

\section{O crescimento demográfico e seu impacto econômico}

Uma parte dos neomalthusianos consideram o crescimento demográfico como o elemento básico da geração de impactos sobre o meio ambiente. De fato, o aumento populacional gera requerimentos maiores sobre os recursos e podem provocar, por outro lado, imṕactos perversos sobre a poluição ambiental.

O crescimento demográfico pressiona as necessidades, forçando o setor produtivo a trabalhar em um ritmo tal que pressiona a demanda por recursos que, por sua vez, tendem requerer custos crescentes de exploração, fazendo seus preços subirem.

É uma distorção, porém, achar que este é o elemento determinante. A população incide sobre o meio ambiente conforme o sistema sócioeconômico no qual ela está inserida. Um exemplo disto é a grande diferença neste impacto, quando se 
considera populações tão diferenciadas quanto aquelas do Terceiro Mundo e as da Europa Ocidental e dos Estados Unidos.

\section{A articulação sócio-econômica e seu impacto sobre o meio ambiente}

A quase totalidade dos economistas neomalthusianos que projetam o futuro, assumem que a tendência catastrófica é inevitável, exceto que a velocidade do processo de crescimento seja reduzida. Neste sentido é que aparece a proposta inicial do próprio Clube de Roma, de uma estagnação deliberada da taxa de crescimento - crescimento zero como forma de evitar-se o desastre.

Esta proposta decorre, por sua vez, da concepção mecanicista e metafísica de imaginar o problema como puramente econômico, decorrente do aparelho produtivo, e de considerar a estrutura social como um dado rígido. Isto leva a entender o impacto sobre o meio ambiente como um problema decorrente da oferta gerada pela economia (e seus requerimentos e sua poluição) e não como decorrente da demanda - quantitativa, mas também qualitativa - que a sociedade exerce sobre o aparelho produtivo. Finalmente, não considera o fato de que o impacto econômico decorre diretamente, em muitos casos, menos de efeitos físicos do que de características sociais.

A realidade, porém, é que o impacto sobre o meio ambiente é uma conseqüência direta de cada estrutura sócio-econômica específica. Cada pequeno efeito devido a cada setor específico se repete em uma malha complexa de subsetores e seus respectivos efeitos, compondo a rede da articulação sócioeconômica e seu impacto sobre o meio ambiente. Desta malha de articulações devem participar: padrões de consumo, estrutura urbana, valores culturais, nível de inovação técnica, etc.

De todos os valores que compõem a articulação dos impactos ambientais, a mais importante, sem dúvida, é o padrão de consumo da sociedade.

É óbvio que se o efeito ambiental é decorrente da produção e este é decorrente do consumo, o primeiro decorre do último. Um exemplo disto é a indústria automobilística que tem servido como um dos símbolos máximos de perversidade sobre o meio ambiente, ao deteriorar recursos e poluir o ar. A indústria automobilística decorre diretamente de um determinado padrão de consumo que generalizou o uso do automóvel privado como meio de transporte. Isto leva a um uso exagerado de recursos (petróleo, ferro, etc.) necessários e de poluição gerada por cada unidade de transporte (passageiro/quilômetro).
O automóvel é apenas o símbolo de um sistema mais amplo que modernamente se chama de consumismo. Esta característica básica da moderna sociedade capitalista é necessariamente depredativa e poluente, graças a dois aspectos: ela requer uma produção permanentemente crescente no máximo possível, e se baseia na procura persistente de uma redução nos custos de produção. Tanto a produção crescente como a redução nos custos tende, por um lado, a poluir e, por outro, a depredar. A produção crescente gera, inicialmente, uma depredação no lado dos recursos, e depois, no uso, gera uma poluição devido ao desperdício. Isto torna-se mais visível quando se observa a "civilização do descartável" como forma de dinamizar a economia através do consumismo esquizofrênico. Da mesma forma que este consumismo requer recursos aceleradamente crescente, ele joga no meio ambiente uma soma de resíduos de difícil reciclagem, e que não sendo biodegradáveis (latas de alumínio, garrafas de plástico, etc.) tornam-se em agentes poluidores.

Os efeitos sobre o meio ambiente são, assim, decorrentes do estilo civilizatório onde se situa a economia. Neste sentido, o problema não pode ser estudado sem se tomar em conta toda a articulação sócio-econômica na qual o problema se situa.

\section{O aparato tecnológico e os efeitos sobre o meio ambiente}

Embora o nível de tecnologia prevalecente na economia seja função do sistema sócio-econômico, é possível entender o subsetor específico da tecnologia como tendo efeitos particulares sobre o meio ambiente.

Isto quer dizer que, dado um estilo de civilização, é possível diferentes caminhos para satisfazêlo, seja graças a pequenas modificações no padrão de consumo, seja devido a aspectos específicos da tecnologia. Um exemplo disto pode ser dado pela comparação no sistema de transporte entre dois padrões de consumo dentro do mesmo estilo de civilização: A Europa Ocidental e os EUA.

Cada padrão tecnológico tem suas características poluentes e depredadoras. Por isto, no centro do problema do meio ambiente está o problema tecnológico, que por sua vez é decorrente da estrutura sócio-econômica.

O problema torna-se mais grave no caso das sociedades que importam tecnologias de países com maior nível de desenvolvimento. Estas tecnologias ao serem transpostas, trazem todos os seus componentes depredativos e poluentes com dois agravantes: a pobreza tecnológica e de recursos não permite o desenvolvimento de técnicas de comba- 

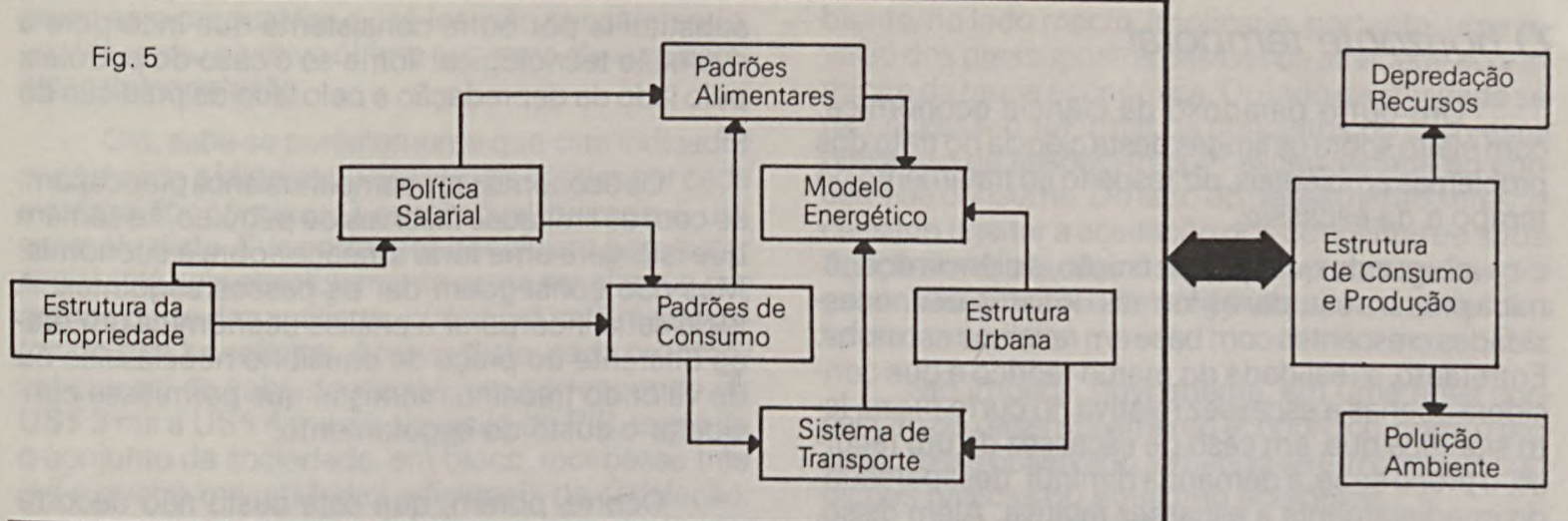

te à poluição ou o desenvolvimento de recursos alternativos; o desenho das tecnologias com base em recursos diferentes dos locais faz com que as economias importadas requeiram importação desses recursos, gerando uma forma diferente de depredação através da dívida externa. Ao nível nacional, a depredação se dá diretamente sobre outros recursos (inclusive o trabalho humano) utilizados para gerar divisas que permitam a importação.

\section{O problema do preço na escassez real}

A dificuldade em projetar, com segurança, o progresso técnico, torna impossível definir as conseqüências econômicas, ou seja, os custos de depredação de recursos. Se a tecnologia, "de repente", substituísse o petróleo como fonte básica de energia, a depredação do meio ambiente pelo automóvel deixaria de ser um sintoma importante.

\section{Os limites da ciência econômica}

Em relação ao problema ecológico, os economistas podem estar divididos nos seguintes grupos:

- aqueles que não reconhecem o problema: os neoclássicos, porque crêem que o mercado resolverá, e alguns que se assumem marxistas porque, por um lado, o processo social resolverá o problema, e, por outro lado, porque consideram o tema como uma espécie de disco voador ideológico, jogado no debate para desviar as atenções da verdadeira dimensão da crise do sistema capitalista;

- aqueles que se preocupam com o problema: os que propõem o crescimento zero como alternativa e os que entendem o problema como de origem da estrutura sócio-econômica e esperam modificações neste nível.

Em todos os casos percebe-se uma limitação na teoria econômica que a impede de captar o problema do meio ambiente em toda dimensão.
Estes limites decorrem dos seguintes aspectos: a visão nacional dos indicadores econômicos; a visão de curto prazo na consideração da escassez apenas relativa; a impossibilidade de prever com segurança mudanças no conhecimento técnico; a impossibilidade de prever mudanças nas estruturas sociais; as dificuldades da ciência econômica em considerar realmente os fins mais reais do homem em vez dos meios; as dificuldades de medir custos e benefícios.

\section{A visão nacional}

Apesar de que a teoria econômica seja deliberadamente cosmopolita, no sentido dado por Adam Smith de considerar o livre comércio como base para o crescimento amplo da economia, na realidade, toda contabilização econômica é dada ao nível nacional lou ainda mais específico, ao nível de unidades estaduais, municipais, empresariais ou, mesmo, individuais). Em nenhuma hipótese a unidade de contabilização atinge o nível mundial. O máximo de unidade considerada é a Nação ${ }^{12}$. Embora esta unidade seja correta para os fins de consideração sobre o bem-estar social, e seja capaz de permitir a consideração sobre a poluição, ela é incapaz de incorporar todos os efeitos da economia sobre o meio ambiente, do lado da depredação dos recursos.

Um exemplo disto pode ser dado na decisão da OPEP, que ao elevar os preços do petróleo estava de certa forma protegendo um recurso. A análise econômica não consegue, porém, captar esta proteção, uma vez que os efeitos são considerados país por país, e nós países importadores o único efeito considerado é o efeito perverso sobre a balança comercial.

Para que o efeito antidepredativo fosse tomado em conta seria necessário que as reservas totais de petróleo fossem consideradas e que o efeito de sua proteção repercutisse nas contas nacionais. 


\section{O horizonte temporal}

Um outro paradoxo da ciência econômica, com efeito sobre os limites desta ciência no trato dos problemas ambientais, diz respeito ao tratamento do tempo e da escassez.

Segundo qualquer definição, a ciência econômica procura estudar as formas de satisfazer necessidades crescentes com base em recursos escassos. Entretanto, a realidade do marco teórico é que considera apenas a escassez relativa no curto prazo. Isto significa que, em caso de escassez de um recurso, o preço sobe, a demanda diminui, desaparecendo imediatamente a escassez relativa. Além disso, o novo preço propiciará o aparecimento de substitutos que fazem desaparecer a própria escassez.

Isto decorre de que a ciência econômica neoclássica considera apenas os desequilíbrios no curto prazo, e Marx tomava o longo prazo explicado pelo materialismo histórico, colocando as leis do capitalismo apenas dentro de horizontes determinados do tempo, durante os quais não considerava o risco de escassez real, posto que o sistema socialista substituiria o capitalismo, reequilibrande a relação do homem com a natureza.

Esta visão, de ambas as escolas, parece não verificar-se completamente. O capitalismo moderno, com sua sociedade de consumo, parece requerer uma depredação crescente de recursos, em uma velocidade tal que pode gerar escassez real de certos recursos, antes que o conhecimento técnico encontre substitutos e que a sociedade se transforme sem custos sócio-econômicos graves.

Não é fácil, porém, à ciência econômica, encontrar formas de tomar em conta o longo prazo, devido à impossibilidade de prever as mudanças na sociedade ou no nível técnico. De certa forma, as leis da ciência econômica têm sido incapazes de modificar-se com a mesma rapidez com que muda o seu objeto de estudos.

\section{As mudanças no conhecimento técnico}

A teoria econômica moderna (neoclássica ou marxista), sob formas diferentes, mantém um otimismo constante em relação ao avanço técnico. Assume-se que o homem será capaz de resolver os problemas do sistema econômico dentro de um prazo hábil para evitar custos.

$\mathrm{Na}$ medida em que a realidade dos últimos anos começa a jogar dúvidas sobre o assunto, os economistas sentem-se desamparados, em dúvida com a teoria de que dispõem, mas sem forma de substituí-la por outra consistente que incorpore a evolução tecnológica. Tome-se o caso do petróleo, pelo lado da depredação e pelo lado da poluição do ar.

Os economistas neomalthusianos preocupamse com as limitadas reservas de petróleo ${ }^{13}$ e sentem que isto gera uma forte ameaça sobre a economia. Mas não conseguem dar os passos seguintes. A idéia seria incorporar à análise econômica um preço diferente do preço de equilíbrio neoclássica ou do valor do trabalho marxista, que permitisse considerar o custo do esgotamento.

Ocorre, porém, que este custo não decorre apenas do nível de consumo, mas também das possibilidades técnicas de substituir este recurso por um outro. Assim, se descobrem substitutos, os efeitos da escassez desaparecem e o recurso valioso é aposentado e perde seu valor.

O mesmo ocorre se consideramos o problema do lado da poluição. O efeito da poluição gerada pelo uso do petróleo pode ser medido em termos do custo das medidas de purificação do ar. Entretanto, é impossível saber o custo exato. Caso sejam descobertas formas baratas (inclusive com o uso da engenharia genética) de combate à poluição, ou tipos especiais de "motores limpos" que não geram resíduos, a preocupação embiental se tornaria irrelevante.

É, porém, impossível prever as possibilidades reais de que estas descobertas avancem, como é difícil prever a possibilidade e dimensão das transformações na estrutura social.

\section{Mudanças sociais}

Em caso de modificação na estrutura social, o nível de consumo global e de certos recursos tendem a modificar-se, acelerando-se a pressão sobre alguns e liberando sobre outros. Isto faz com que os resultados ambientais sejam modificados rapidamente e em proporções inesperadas.

\section{Os meios e os fins}

Além de analisar suas relações dentro das fronteiras das nações, e no curto prazo, a ciência econômica, por uma alienação epistemológica, por simplificação ou por defeito congênito, limita-se a ignorar objetivos finais do processo econômico e concentra-se apenas no final direto de seus produtos que correspondem apenas aos meios, se tomados em uma perspectiva mais ampla.

O indicador básico da economia, o PIB, serve para indicar isto. Medido nacionalmente, o PIB considera apenas os efeitos imediatos dos produtos, não tomando em conta os custos entrópicos de longo 
prazo para produzi-los e usá-los, não considerando, em fim, o seu objetivo último que seria elevar o bemestar da população.

Ora, sabe-se perfeitamente que este indicador peca devido a idiossincrasias sociais criadas por cada sistema econômico. O automóvel privado é um exemplo disto. Sua correspondência em bem-estar social está hoje absolutamente posta em cheque por grande parte dos analistas, que vêem nele mais custos do que benefícios. Apesar disto, cada automóvel que sai de linha de montagem corresponde de US\$ 3 mil a US\$ 4 mil de elevação do PIB como se o conjunto da sociedade, em bloco, recebesse três mil a quatro mil unidades adicionais de satisfação.

Isto limita a possibilidade de que a ciência econômica possa, através de seus indicadores, determinar o impacto sobre o meio ambiente, uma vez que os seus indicadores não refletem um bem-estar real, e daí, não pode-se determinar o custo (em bem-estar) de um equilíbrio ecológico. Em função dos atuais indicadores estes custos seriam mais elevados do que na "realidade".

\section{A incorporação do problema ecológico na análise econômica: algumas sugestões}

O problema do uso de instrumentais econômicos para considerar e solucionar os problemas de desequilíbrio ecológico, deve ser encarado sob dois pontos de vista: o lado macroeconômico e o lado microeconômico.

\section{O problema do lado macro}

No lado macro, a economia deve considerar que seu impacto sobre o meio ambiente é decorrente de dois vetores que se juntam criando as bases ideológicas da chamada sociedade de consumo. 0 primeiro vetor corresponde à visão otimista da história e da capacidade infinita de inóvação tecnológica que permitiria uma dinâmica sem limites do processo de transformação da natureza em bens e serviços. O segundo vetor corresponde à ânsia consumista que o capitalismo identifica na oferta esquizofrenicamente acelerada de bens e serviços (incluindo as não-mercadorias) ${ }^{14}$ como sendo a própria razão de ser da atividade econômica.

Estes dois vetores são os responsáveis básicos pela ideologia do crescimento ilimitado, em conseqüência da qual a macroeconomia se orienta relegando os impactos sobre o meio ambiente, tanto no que se refere à depredação dos recursos, como à poluição do meio ambiente.

A solução do problema economia-meio am- biente, no lado macro, implicaria, portanto, uma revisão dos pressupostos básicos da atividade econômica e da teoria econômica. Do lado da atividade seria necessário reformar os conceitos de bem-estar deixando de associá-lo com exclusividade ao conceito de consumo. Do lado do pensamento seria necessário rejeitar a aceitação dos conceitos de substituição imediata de uns recursos por outros, seja graças às leis de mercado, ou graças exclusivamente a reformas sociais.

Isto implica, obviamente, em uma nova concepção do desenvolvimento econômico, onde o processo fosse observado tomando-se em conta as condições básicas do equilíbrio ecológico.

É certo que este equilíbrio não pode ser integralmente obtido com o sistema capitalista tradicional, onde a "liberdade" de mercado e a concorrência implicam necessariamente em uma miopia temporal e em custo apenas privatizados que forçam o menosprezo da deterioração dos recursos e da poluição, as quais recaem, ambas, sobre o longo prazo e sobre toda a sociedade.

O socialismo, por sua vez, não resolve necessariamente o problema, se se concentra apenas na boa distribuição social do produto entre as gerações presentes e segue acreditando na onipotência da tecnologia.

A solução do problema economia-ecologia só pode ser dado em uma consciência global no sentido social e temporal, ao mesmo tempo em que se desatrela o indicador econômico de suas amarras basicamente produtivas e materiais, incorporando-os em uma visão ecologicamente equilibrada, na qual o bem-estar dos indivíduos não são, tampouco, univocamente identificados com o consumo de bens ${ }^{14}$.

\section{O problema do lado micro}

Apesar do problema ser visto primordialmente a nível da estrutura social - macroeconomicamente - a deterioração e a poluição se dão fisicamente ao nível microeconômico de cada unidade de produção e de cada unidade de consumo.

Em outras palavras, o efeito da economia sobre o meio ambiente é dado diretamente pelas fábricas, fazendas, etc., tanto na depredação como na poluição; e diretamente pelos usuários dos produtos, tanto pela demanda que geram lespalhada ao nível macro) como na poluição do uso dos produtos: automóveis, desperdícios, etc.

Se é certo que o nível macroeconômico e o ideológico definem o micro, é também certo que a teoria econômica - no capitalismo atual ou em um sistema ecologicamente equilibrado - deve tomar 
em conta e medir os impactos diretos ao nível micro, de cada unidade de produção e de uso, na tomada de decisões concernentes aos investimentos.

Teoricamente, a metodologia que permitiria isto seria uma modificação na teoria dos preços, tanto neoclássico como marxista, que permitisse, de um lado, neoclássico, incorporar os efeitos de longo prazo sobre o mercado e os custos sociais nãoprivatizáveis; do outro, marxista, incorporar um valor intrínseco aos recursos naturais na formação do valor latualmente identificado apenas ao valor trabalhol; além disso, para ambos os casos seria preciso considerar o custo necessário para reequilibrar os efeitos ecológicos devido à poluição.

É óbvio que a transformação nos preços de mercado nas economias capitalistas não pode ser realizado pelos próprios empresários, uma vez que isto (o longo prazo e os custos sociais nãoprivatizáveis) chocam-se com a própria racionalidade dos empresários e de cada consumidor tomado individualmente. Mas em todas as economias capitalistas, especialmente aquelas do Terceiro Mundo, - Estado dispõe de mecanismos de intervenção e controle que permitem induzir, orientar ou controlar a atividade produtiva no sentido de considerar os efeitos depredativos e de poluição sobre os preços.

Se a mecânica de administração não é difícil de ser aceita, em compensação torna-se difícil estimar as correções necessárias aos preços de mercado. Uma proposta éno sentido de que os órgãos governamentais encarregados de aprovar projetos, ao analisá-los, ajuste os preços de mercado aos preços econômicos conforme as metodologias já disponíveis ${ }^{16}$, e além disso, utilizem um ajuste adicional que transforme os preços econômicos de curto prazo em custos econômicos de longo prazo, considerando-se os efeitos sobre a disponibilidade de cada recurso natural.

Nas economias socialistas o problema de formação de preços pode ser realizado de forma ainda mais simples, uma vez que a racionalidade dos mesmos já incorpora a socialização dos custos na soma dos trabalhos. Se tornaria necessário apenas considerar um valor para o recurso natural, com base na escassez reall ${ }^{17}$.

\section{Notas}

1. Conforme The entropy law and the economic process, de $\mathrm{N}$ Georgescu-Roegen. Harvard University Press, Cambridge, 1974.

2. Os "serviços" são, por sua vez, decorrentes do uso de certos tipos de bens e de trabalho.

3. Centenas de milhões de anos seriam necessários para repor o petróleo gasto, através da transformação de matéria orgânica.

4. Um aspecto social interessante, que será relegado neste arti- go, diz respeito à depredação de aspectos da natureza que não correspondem a recursos econômicos, mas têm um valor social. É o caso, por exemplo, de um projeto hidráulico lenergia e irrigação) no Vale do Tennesse, entre outras conseqüências estavam a "inundação" de um lago onde uma espécie de peixe vivia em um microambiente que seria destruido, extinguindo definitivamente esta espécie de vida animal; ou do projeto da represa de Assuan que cobriu uma área arqueologicamente de grande valor histórico. Do ponto de vista econômico são despreziveis as conseqüências desta destruição e do ponto de vista histórico-social isto pode ter um grande valor.

5. Um exemplo dramático disto se reflete no caso de Cubatão, onde, devido à poluição, grande número de pessoas sofre de doenças das vias respiratórias e até mesmo deformações congênitas, como nascimento de crianças sem cérebro.

6. Um exemplo destas duas possibilidades encontra-se na "limpeza" do Rio Tâmisa em Londres, voltando a ser fértil depois de séculos de poluição; ou no aproveitamento do vinhoto das destilarias de álcool, evitando-se descarregá-los nos rios próximos.

7. É esta visão que fez com que o professor Friedman, Prêmio Nobel de economia, tenha assegurado, em 1974, que os preços do petróleo cairiam rapidamente, graças a substitutos que seriam encontrados.

8. Na realidade, as discordâncias dos teóricos neoclássicos sobre a teoria de inovação, sempre se deu sobre o processo dessa inovação, mas nunca pondo em dúvida este pressuposto.

9. Um exemplo disto pode ser explicado com respeito ao petróleo. Quando ele se torna escasso, é necessário buscá-lo em lugares mais dificeis, como o Mar do Norte, o que requer mais trabaIho, elevando o valor.

10. A agricultura na água, por japoneses, e a revolução verde são exemplos bastante elucidativos. E a engenharia genética pode vir a ser uma nova revolução, liberando, talvez, no futuro, a agricultura do próprio solo.

11. Existe uma vasta literatura sobre o assunto. Basicamente, convém citar os seguintes trabalhos: MESAVORIC, M. \& PESTEL, E. Mankind at the turning point; the second report to The Club of Rome. New York, Dutton \& Co., 1974. MEADOWS, D.H. \& MEA DOWS, DL. The limits to growth. S.1, New American Library, 1972.

12. A conceituação da teoria de Adam Smith como sendo "cos mopolita" foi usada inicialmente por Friedrich List, em 1841, de quem é a frase: "Entre o indivíduo e a humanidade está a Nação".

13. São muito discordantes as projeções sobre reservas de petróleo e ainda mais aquelas que vinculam estas reservas com o nivel de consumo.

14. O conceito de não-mercadoria é no sentido dos bens que não servem ao consumo dos individuos, como os armamentos. Sobre o assunto ver trabalho do professor Lauro Campos da Universidade de Brasilia.

15. Conforme Stratégies de l'Écodeveloppent, de I. Sachs. Les Éditions Ouvrières, 1980.

16. A bibliografia básica do assunto está em três livros: MARGLIN, Dasjupta \& SEN. Project evaluation guidelines. Viena, ONUDI. 1972; LITTLE \& MEIRRLEES. Project appraisal and planning, for developing countries. New York, OCDE, 1972. Basic Books, e SQUIRE \& VAN DER TAK. Avaliação econômica de projetos. S.1 Banco Mundial/ John Hopkins Un. Press, 1975.

17. Uma proposta neste sentido está desenvolvida nos trabalhos do autor deste artigo, publicados pelo Departamento de Economia da Universidade de Brasilia, Necessidades básicas, avaliação de projetos e distribuição de rendas lentre classes e entre gerações) texto para Discussão n. 59 , e Neomathusianismo e avaliação de projetos, a ser publicado na Revista Pernambucana de Desenvolvimento. 